\title{
Modos de relación sintiente Bocetos hacia una perspectiva del performance como ruta metodológica para la indagación de subjetividades*
}

\author{
MODES OF SENSITIVE RELATION \\ FIRST REFLECTIONS ON A PERFORMANCE PERSPECTIVE AS A ROUTE FOR \\ METHODOLOGICAL ENQUIRY SUBJECTIVITIES
}

MODOS DE RELAÇÃO SENSÍVEL

ESBOCOS PARA UMA ROUTE METODOLÓGICA PARA A PESQUISA DAS

SUBJETIVIDADES

\section{Sonia Castillo Ballén**}

Cuadernos de Música, Artes Visuales y Artes Escénicas

/ Volumen 10 - Número 1 / enero - junio de 2015

ISSN 1794-6670/ Bogotá, D.C., Colombia / pp. 129-150

Fecha de recepción: 26 de agosto de 2014 | Fecha de aceptación: 24 de octubre de 2014 | Disponible en línea: 29 de mayo de 2015. Encuentre este artículo en http:// cuadernosmusicayartes.javeriana.edu.co/ doi:10.11144/Javeriana.mavae10-1.mrsb

* Artículo de investigación

* Profesora de planta asociada de la Facultad de Artes ASAB de la Universidad Distrital Francisco José de Caldas. 


\title{
Resumen
}

Desde una práctica creativa reflexionada, el texto presenta una crítica sobre la condición política del sentir y esboza el performance como camino para interrogar los modos de relación sintiente hegemónicos aprendidos y poco reflexionados desde las artes.

Palabras clave: modos de relación sintiente; cuerpo; sensibilidades

\begin{abstract}
From the reflection of a creative practice, this paper presents a review on the political status of feeling, and outlines the performance as a way to interrogate the hegemonic sentient relationship modes, which are learned and unreflected even from the arts.
\end{abstract}

Keywords: relationship; sentient modes; body; sensitivities

\section{Resumo}

A partir da reflexão de uma prática criativa o texto apresenta uma revisão sobre a condição política de sensibilidade, e descreve o performance como uma forma de interrogar os modos hegemônicos de relacionamento sensível, que são aprendidos e irrefletidos mesmo das artes

Palavras-chave: modos de relacionamento sensível; corpo; sensibilidades 


\section{A MANERA DE INTRODUCCIÓN}

Sentir es una acción política que aprendemos a ejercer a partir de procesos previos de formación y educación, así como de reproducciones e incorporaciones que llevamos a cabo a partir de la interacción cotidiana con las disposiciones y órdenes corporales de los ámbitos sociales y culturales en que habitamos. La formación de la infancia constituye, en buena medida, un proceso para domeñar las potencias corporales sensibles, las cuales son, hasta ese momento y por naturaleza, potencias exploratorias y vinculantes con el mundo vivo.

La imitación-reproducción del habitus (Bordieu, 1990)ํำ en la interacción humana y social como dispositivo a través del cual se ha dado el aprendizaje perceptual ha sido, en Occidente, históricamente política pues, lejos de tener la neutralidad objetiva o 'asepsia' experimental que pretenden los estudios de la percepción, dicho dispositivo ha implicado la incorporación de formas de ordenamiento del mundo y de sus componentes, manifestaciones corporales en escalas, clasificaciones y jerarquías de valoración biopolítica. Muestra de ello es el énfasis en la valoración de lo visual y lo mental que ha caracterizado la cultura en Occidente en consecuencia conllevado una incomprensión naturalizada -casi una ceguera- en relación con los procesos estésicos propios de las potencias olfativas y táctiles, entre otras. El énfasis en la relación visual-mental que Regis Debray (1994) argumentó en su trabajo Vida y muerte de la imagen, ha determinado la comprensión del mundo a partir de lo que se ve, en una tendencia que obedece a lógicas de la espacialización, a partir de las dinámicas de valoración perceptual de lo que se ve a la distancia entre el sujeto que observa y el objeto que es observado. Lo anterior, equivale a decir, hacer valoración desde la fragmentación matemática de planos, en intervalos de cercanía o alejamiento, cuyas implicaciones no atañen solamente a la dimensión física, sino que proyectivamente, se manifiestan también en lógicas mentales. Entre ellas están las relaciones de distancia y acercamiento, que pueden interpretarse, para el caso de la ciencia, en la tensión que se da entre objetividad-subjetividad; y para el caso del arte, en la tensión entre subjetividad y contemplación.

De tal manera que aun, cuando por naturaleza, la condición de ser seres corporales es justamente tal, en tanto existen las potencias sensibles, las cuales caracterizan dicha condición, es desde el carácter histórico-político de la interacción humana y social que se aprende a ser 'sintiente' de una u otra manera, frente a cada contingencia específica. El acervo de conocimientos que los seres humanos hemos producido respecto al mundo, respecto a la vida y respecto a nosotros mismos, además de informarnos del desarrollo histórico, de las diferentes maneras de pensar y razonar sobre los fenómenos, también delata las distintas rutas que se han privilegiado para comprender y ejercer las condiciones sensibles y las facultades sintientes.

Aun cuando estas dinámicas del aprender a sentir son situadas y contextuadas según sociedades y épocas para el caso de occidente, es posible ver cómo estructuras iniciales básicas de estas lógicas del régimen visual-mental aún prevalecen y se reproducen como dinámicas para la valoración de experiencias estéticas en la vida cotidiana y en los medios de comunicación. Con lo anterior, me refiero puntualmente a la reproducción aún vigente de estructuras de valoración en relación con aspectos sensoriales, funcionales y orgánicos del mundo, a partir de lógicas de "semejanza", de "diferenciación" (entre características animales y humanas), o de oposición (por ejemplo, entre lo femenino y lo masculino) las cuales, soportadas en los albores de occidente por perspectivas como la Fisiognomía aristotélica (Martínez \& Delcán, 1999), 
contribuyeron en buena medida, a sentar las bases de concepciones como el antropocentrismo, la comprensión de la vida desde el fin humano, la clasificación racista de las corporeidades humanas o la sub-valoración histórica de la condición femenina en occidente. Algunas de estas jerarquías del orden corporal bio-político ya pueden verse casi explícitas en las siguientes teológicas en dicha Fisiognomía, que refiero a manera de ejemplificación:

Y de manera similar sucede en las razas humanas, dado que aquellos que habitan en zonas septentrionales son valientes y de cabellos hirsutos, mientras que quienes viven en regiones meridionales son cobardes y lacia su cabellera. (Debray, 1994, p. 47)

El color que conforme la virilidad debe estar a mitad de camino entre estos extremos. Los rubios son animosos: es el caso de los leones. Los de color bermellón son astutos: véase los zorros. Por su parte, los de color ligeramente pálido y enturbiado son cobardes, como se comprueba por el estado anímico que resulta del miedo. Los que son demasiado morenos son cobardes: piénsese en los egipcios y los etíopes. También son cobardes los que son demasiado blancos: es el caso de las mujeres. (Debray, 1994, p. 52)

Y por otra parte, es igualmente evidente que en cada especie las hembras tienen la cabeza más pequeña que el macho, la cara más estrecha...Sus piernas son delgadas y se entrechocan al andar, sus pies son más elegantes, y todo su aspecto físico es especialmente agradable antes que noble, pero son más flojas y muelles, y de carnes más húmedas. En cambio, los machos son todo lo contrario, al ser su sexo de una naturaleza más viril y bondadosa, mientras que el de la hembra es más pusilánime y perverso. (Debray, 1994, p. 59)

En términos generales, las lógicas del orden corporal bio-político han sido legítimamente puestas en marcha e institucionalizadas, a través de los ámbitos académicos, no solo de disciplinas como la biología o la educación física, tal como señala la antropóloga colombiana Zandra Pedraza (2004), sino también del campo artístico, mediante las lógicas estructurales que han puesto en circulación los distintos paradigmas estéticos sobre lo sensible, a través de los procesos de legitimación de las prácticas formativas de artistas. Esto ha contribuido a la educación bio-política de las sensibilidades, a partir de concepciones, valoraciones y modos de representación basados en dinámicas de jerarquización de la condición corporal de la existencia.

Tal como lo señala Katya Mandoky en Prácticas Estéticas e Identidades Sociales (2006):

Mientras la teoría estética ortodoxa se vuelca minuciosa y reiteradamente sobre los mismos problemas desde hace un cuarto de milenio (e.g. la objetividad de lo bello o la definición y límites del arte), en la práctica atestiguamos en total indefensión conceptual el desarrollo de una verdadera tecnocracia de la sensibilidad, psico-ingenierías de la subjetividad y boyantes estéticas de la violencia. Por ello, es cada vez más difícil refutar que muchos de los problemas más graves de la sociedad contemporánea pudieran estar directa, aunque no exclusivamente, relacionados con la estética. Me refiero a la drogadicción, racismo, delincuencia, suicidio, alcoholismo, violencia doméstica, pornografía, obesidad e incluso enfermedades emocionales como la depresión crónica, anorexia y desórdenes obsesivos y compulsivos en países altamente tecnologizados. Lo están porque entre las condiciones primordiales para la sobrevivencia física y mental del ser humano está su dignidad estética. La violencia psicológica que deriva en el crimen, el fanatismo militante y la patología social también pasa por la sensibilidad vejada del individuo. (p.9) 
En este sentido, la reflexión que se lleva a cabo en este texto propone una revisión crítica respecto a aspectos que se refieren a la vigencia de un estatuto corporal de perspectiva biopolítica (Pedraza, 1999) en las artes, en particular, en las formas del lenguaje y de las prácticas en las artes plásticas. Las ideas que aquí presento, reúnen algunos resultados de la investigación que he realizado sobre este tema mediante procesos de indagación sobre la valoración de la condición corporal de artistas en formación en ámbitos universitarios nacionales. Dicha indagación se llevó a cabo a través de prácticas de creación-investigación, reunidas en el proyecto Anatomías sentimentales: corpografías desde las artes del cuerpo, en los cuales el performance fue asumido como la posibilidad investigativa de subjetividades. En estas anatomías sentimentales o corpografías, el performance, además de ser explorado en su potencia creativa, fue asumido abiertamente como ruta metodológica -que no método- en la que intervienen formas distintas de la observación como la auto-observación y la observación participante. Esta ruta provoca un dinamismo vital en la interpretación permanente entre aspectos émicos y éticos de la investigación, bien sea que dicha interpretación sea de carácter colectivo, o de carácter personal.

En el proyecto en mención, en las dinámicas del performance se indagaron aspectos de la configuración de subjetividades, rastreados mediante la observación y el registro de intersensibilidades utilizando recursos escriturales, del dibujo, sonoros, fotográficos, y de corte autobiográfico o narrativo. En estos ejercicios, los diarios de notas en sus modalidades de diarios de campo y diarios intensivos fueron tomando en ocasiones la configuración de bitácoras o libros de artista con énfasis reflexivo. Sin embargo, el presente texto hace énfasis no en el cómo del uso de estos recursos sino en la fundamentación de argumentaciones que fueron necesarias para poder asumir el performance y las corpografías no solo como lenguajes artísticos, sino también como rutas metodológicas propicias para la indagación de subjetividades.

La indagación aquí es tomada como una posición que vincula tanto elementos propios de la actividad investigativa como recursos creativos de las artes. Indagar desde la investigacióncreación para poder comprender. Hablo de interpretación apoyándome en el sentido relacional que Gadamer (1977, p. 378) establece entre interpretación y comprensión:

La interpretación no es un acto complementario y posterior al de la comprensión, sino que comprender es siempre interpretar, y en consecuencia la interpretación es la forma explícita de la comprensión.

El desarrollo metodológico del proyecto se realizó en un contexto de tensiones entre los avanzados discursos que circularon sobre posmodernidad y trans-modernidad en los ámbitos artísticos universitarios nacionales en la primera década de lo que va corrido de este siglo, en contraste, con el arraigo de prácticas modernas en la valoración de la participación de la condición corporal en los procesos creativos. Los procesos de formación de artistas aún modernistas apenas si iniciaban por entonces la elaboración de pronunciamientos acerca de las implicaciones políticas que tiene la formación de corporeidades para y desde las artes. En consonancia, la indagación en mención partió básicamente de asumir la condición corporal como contingencia política de la existencia.

Bajo estas premisas emergieron con fuerza dos realidades: La primera en relación con la certeza de enraizamientos modernos para la valoración de las mujeres como artistas, o como artistas maestras, y la segunda en relación con una gran pluralidad en cuanto a las maneras de nombrar 'el cuerpo', las cuales, si bien coincidían en esta última denominación como concepto 
común aprendido a fuerza de procesos educativos, también adoptaban una pluralidad de denominaciones específicas atendiendo a situaciones de subjetividades, edades, géneros, razas y episodios autobiográficos.

Asumiendo la perspectiva del investigador mexicano Arturo Rico Bovio en Fronteras del cuerpo. Crítica a la corporeidad (2006), esta pluralidad:

"da cuenta y nos deja darnos cuenta" de los distintos momentos, avances y retrocesos en la conformación de niveles de "consciencia histórico reflexiva" como "consciencia estimativa" manifiesta (...) en niveles biológicos, físicos, personales, sociales, psíquicos, noogénicos, energéticos. (p.71)

Con esto, para la investigación se hizo notorio que los distintos niveles, momentos e intensidades de esta consciencia estimativa, daban cuenta de la experiencia corporal de la existencia como una condición, en tanto estado inacabado y variable, plástico en su capacidad de acrecentarse o detenerse; condición, en tanto la consciencia estimativa de la experiencia corporal dependía también de las circunstancias de género, de historias y contextos, de memorias de lo vivido, etc., por lo cual, la investigación optó entonces por un intento de vínculo relacional de estas pluralidades bajo la expresión "condición corporal."

Dicha expresión favoreció el poder penetrar en la experiencia política de la existencia, y las implicaciones que esta conlleva; para el caso puntual, las maneras de vida de las mujeres que participaron en el proyecto. Condición en un sentido amplio de interpretación, conlleva la experiencia de ir siendo, un estado "situado" y "circunstancial", además de las implicaciones de sinónimos que tiene esta denominación: jerarquía, posición, clase, categoría.

Lo anterior, teniendo en cuenta que según se diagnosticó en la investigación en mención, durante la primera década de lo que va corrido de este siglo, con contadas excepciones, en el ámbito de la "enseñanza" de las artes aún prevalecía, una comprensión constreñida de la condición corporal, básicamente reducida al cuerpo concepto cosificado, a la manera de conceptoobjeto propicio para el ejercicio técnico y la producción de obra, donde todavía se reproducía "el olvido sistemático de la condición corporal del sujeto artístico en el arte de la modernidad", al que alude Amelia Jones, en El cuerpo del artista (2006).

Teóricamente, el tratamiento de los pilares y recurrencias que dieron forma al diálogo de autores y fuentes al interior de la indagación, se basó en estudios que contribuyen a una perspectiva crítica sobre la condición corporal en Colombia y Latinoamérica²; así como en estudios sociales, psicológicos, feministas, culturales y de antropología sensorial ${ }^{3}$ y, estudios artísticos y estéticos que hacen contribuciones al tema del cuerpo en las artes ${ }^{4}$

Para el análisis e interpretación de la información conseguida se hizo necesaria la fundamentación de un recurso que fuese propicio para la valoración de la base de datos compleja, obtenida de muy diversas fuentes, que se concretó en la propuesta del criterio teórico y metodológico de modos de relación respecto al cuerpo o modos de relación sintiente, a través del cual se llevó a cabo la interpretación relacional de aspectos como: las dinámicas del intercambio estésico (sensible-sintiente) vividas por artistas en formación en ámbitos de experiencias creativas desde el performance, donde se comprometía una indagación crítica y política de roles, performatividades y prosaicas sociales ejercidas por dichos participantes en las vidas cotidianas. 


\section{CONFIGURACIÓN DEL CRITERIO DE MODOS DE RELACIÓN SINTIENTE}

En correspondencia con las exigencias que esta indagación tuvo, la conformación del criterio de modos de relación sintiente, estructuralmente, es el resultado en sí mismo de un análisis comparativo entre las recurrencias encontradas a partir de una primera sistematización de la base de experiencias realizadas desde las corpo-grafías y el performance, con otras recurrencias, a manera de habitus académicos, encontrados en las maneras metodológicas de abordar el tema del cuerpo en estudios histórico-críticos de corte interdisciplinar, en perspectivas críticas latinoamericanas sobre la corporeidad (Rico, 1998) y sobre la estética (Mandoky, 2006). Además, se tuvieron en cuenta aspectos como los interrogantes que propone el psicoanálisis sobre el proceso creador: (Anziu, 1997), la pregunta por lo sensible-sintiente de la antropología de los sentidos, y los estudios artísticos sobre el cuerpo.

En un primer momento de la configuración de dicho criterio, la propuesta del "Modelo octádico" de la artista investigadora mexicana Katya Mandoky Prácticas estéticas e identidades sociales. Prosaica dos, (2006), resultó reveladora como estrategia para indagar dinámicas muy específicas de los intercambios del orden sensible-sintiente - "acústico, lexical, somático, escópico; proxémica, cinética, enfática fluxión" (p. 22) -llevados a cabo por quienes participaron, en busca de no reducir dichos intercambios a una interpretación exclusivamente formal, bien sea desde lo referente a la técnica desde el lenguaje artístico o a la puesta en escena, o al riesgo de la fragmentación de la experiencia que puede conllevar el análisis de contenido o de actos de habla, por sí solos.

La aplicación del Modelo Octádico de Mandoky (2006, pp.18-69) dio paso a la valoración del carácter político de la experiencia personal y colectiva de intercambios del orden de lo sensible-sintiente que se ponían en juego en las diversas experiencias, según condiciones de género, raza, clase, edad, etc. La aplicación de dicho modelo también permitió esclarecer los arraigos estructurales que se esconden tras las distintas maneras de nombrar la condición de la existencia como "cuerpo," "corporeidad", "corporalidad", "casa", "casita", "alma", "muñeco", "mi apariencia", etc., por mencionar algunos nombres que se le otorgó a dicha condición, a partir de las experiencias personales. La aplicación de este modelo también coadyuvó a la sustentación de la denominación de "condición corporal" de la existencia, como condición estésica, pues se hizo evidente que era esencial. Para Mandoky (p.13) la estésis:

es la condición fundamental de todo ser viviente...la condición de estésis como abertura del

sujeto en tanto expuesto a la vida...Al estar expuesto a la vida y al entorno, el sujeto es atraído

a ciertos elementos según su especie y capacidad...en procesos semio-químicos que involucran tanto significación como atracción, es decir, tanto semiósis como estésis. Se trata, pues, de la condición fundamental de todo ser viviente.

Este hecho permite comprender de manera mucho más concreta a qué nos referimos cuando hablamos de la enigmática palabra "sensibilidad": es la condición de receptividad o porosidad, es decir, de membrana, de todo ser vivo (Mandoky, 2006, p.14)

Así que la valoración que aquí hago, de la condición corporal como condición sensiblesintiente obedece a una interpretación a partir de la síntesis de las dos condiciones ya señaladas. Sensible, en cuanto la condición de receptividad y porosidad, a la vez está condicionada a la mediación psicofísica de la membrana sintiente, la cual, tal como ya lo señaló Didier Anziu (2001) en su Yo Piel, se concreta en la piel, como gran membrana u órgano madre de la per- 
cepción, tanto para los seres humanos, como para los demás seres vivos, destacando el papel que tiene lo sentido en la construcción de principales funciones psíquicas.

La condición sintiente de la piel que constituye una facultad existencial de la persona solo es posible gracias a la plástica de sus porosidades, abultamientos, vellosidades, agujeros etc., a través de cuya geografía toman forma los sentidos. La facultad sintiente de la persona a través de la piel, y mediante los órganos de los sentidos, tiene sentido existencial, en tanto que, es a través de estas cualidades y condiciones sintientes que se llevan a cabo los procesos de intercambio en la interacción social o inter-corporeidades, cuyo movimiento relacional continuo modela la vida, así como el ejercicio de las subjetividades y de las identidades. Para los seres humanos, tal como muestra Anziu (2001), las funciones bio-psíquicas primordiales que cumple la piel permean lo sentido a partir de lo cual se modelan los modos y memorias psíquicas para la configuración del "yo" y las demás categorías de lo que el autor reconoce como aparato psíquico.

La producción autopoiética interpretada por Maturana y Varela (El árbol del conocimiento. Las bases biológicas del entendimiento humano, 2003) tiene como puerta inicial las dinámicas corporales del intercambio sensible-sintiente. Lo vivido cobra sentido a través de lo sentido, y lo sentido modela las significaciones que dan forma a nuestras subjetividades. El intercambio sensible-sintiente a través del cual ejercemos nuestra existencia corporal, se re-crea y se dinamiza también en la compleja red de manifestaciones que conforman nuestra vida corporal interior: imágenes, ideas, pensamientos, recuerdos, sueños, ensoñaciones, fantasías, etc. Pero esta vida corporal interior está imbricada en el intercambio vital de los modos cómo se interactúa con los órdenes del sentir, cómo se valoran y cómo se comprenden en la vida social. El intercambio sensible-sintiente es por lo tanto, políticamente situado, contextuado, encarnado. La experiencia de la existencia no es neutra, ni ocurre desde la idealización objetiva, es una experiencia política; al respecto, señala Rico Bovio: "la actividad de la acción o del movimiento humano, se halla entre lo psíquico y la interacción con el mundo de una personalidad determinada" (1990, p.66). El intercambio sensible-sintiente o inter-sensibilidades ocurre bajo el peso de regímenes corporales específicos. Un ejemplo de esto, puede verse en el tipo de preguntas de investigación que estas reflexiones motivaron en el proyecto. Entre ellas destaco: "¿Cómo he aprendido a sentir y a ser mujer?", ¿Cómo he aprendido a sentir y a ser hombre?"

Las imbricaciones políticas de los intercambios estésico-semiósicos que se dan en la vivencia consciente de lo sensible-sintiente en prácticas como el performance es palpable para quienes lo ejercemos y lo investigamos, en cuanto al tipo de conocimiento que allí se genera, que lo identifico como conocimiento en imagen o conocimiento estésico, cuya rica información acerca de cómo las inter-sensibilidades modelan subjetividades en los límites de las prácticas artísticas, ha sido subvalorada históricamente desde la "duda", por presumir que conduce al error, clasificado como conocimiento inferior, o simplemente como no conocimiento.

Esta última reflexión la hago en cuanto considero que es una necesidad también política para las artes, en particular para los procesos de formación artística, proponer maneras de indagar los conocimientos sensibles o estésicos que se dan en los procesos creadores en artes. Estos no concluyen exclusivamente en las lógicas y propósitos de la creación de la obra, sino que incluyen las aportaciones que hoy las artes pueden hacer respecto de otros modos posibles del ejercicio de las inter-sensibilidades. Estas otras inter-sensibilidades son urgentes, por ejemplo ante los graves daños ambientales que ya vivimos, como consecuencia del ejercicio histórico de la enfática racionalista como modo de relación predominante para concebir, valo- 
rar y representar el mundo de la vida. Es necesario reconocer que el mundo vivo es también un ser sensible-sintiente, y que los modos como hemos ejercido las inter-sensibilidades, por lo menos desde las lógicas bio-políticas, nos muestran hoy las consecuencias referidas.

Al respecto, la crítica a la estética en tanto disciplina, que hace Katya Mandoky (2006), descentraliza el arte como único problema de la misma, y amplía su concepción como: "el estudio de la estesis" (pp. 10-11); abarcando con esto la bio-estética que:

comprendería la cito-estesis o sensibilidad celular, la fitoestesis o sensibilidad vegetal y la zooestesis o sensibilidad animal) como exploración de las criaturas vivas en tanto membranadas y expuestas al mundo (p. 14); (...) la Zoo-estética, anthropo estética: o el estudio de la estesiología animal y antropológica; y la socio-estética: con sus dos componentes, la prosaica o estética de la vida cotidiana, y la poética o estética artística. ( pp. 11-17)

El acervo de conocimientos estésicos que el campo artístico ha desarrollado a fuerza de indagar ámbitos de lo sensible-sintiente a propósito del ejercicio de sus procesos creadores, constituye una contribución para fortalecer las rutas de la indagación de la bio, la zoo y la socio estética. De hecho, en lo que a la socio-estética atañe, prácticas artísticas como el performance, el dibujo, la danza, las teatralidades, entre otras, son asumidas en sus posibilidades metodológicas para estudios sociológicos, antropológicos y culturales sobre estéticas de la vida cotidiana y estéticas populares, entre los que se destacan los estudios de la antropología de los sentidos.

En un segundo momento de configuración, el criterio de Modos de relación sintiente, fue el resultado de un re-ordenamiento estructural de las lógicas de la reflexión que proponen Nadaf, Tazi y, Feher (1992) en Fragmentos para una historia del cuerpo en donde, a partir de la idea argumentada acerca de "modos de construcción del cuerpo", se reúne un número considerable y representativo de estudios del cuerpo provenientes de la historia, la sociología, la psicología, la cultura, la biología, la antropología, la filosofía y las artes entre otros, los cuales, destacan relaciones temáticas disciplinares e interdisciplinares sobre el tema, abordando distintas sociedades y épocas históricas.

La idea de modos de construcción está argumentada por los autores de la fuente citada, a partir de ejes problémicos pensados como los interrogantes más comunes que históricamente los seres humanos se han hecho respecto al cuerpo. Estos ejes problémicos son declarados como comunes en estudios teóricos sobre el tema en las maneras de la representación en el arte, pero a la vez, en relación con aspectos de la vida cotidiana referenciados por cada uno de los estudios compilados.

La sospecha que expresan Nadaf, Tazi y Feher (1992) , en la introducción a la compilación, respecto a la existencia de los modos de construcción del cuerpo que tienden a continuarse a lo largo de la historia de occidente, fue sustentada a lo largo de los enfoques que organizaron los tres volúmenes que comprende la obra.

En el primer eje problémico, "lo humano y lo divino", el autor afirma que la organización de dichos estudios obedece a un enfoque vertical en la relación entre aspectos humanos expuestos comparativamente con lo divino, pasando por lo bestial, y las máquinas que lo simulan. Los estudios muestran cómo la comprensión vertical de la relación entre lo divino y lo humano se proyectó también en los órdenes de las interacciones sociales, e influyó en las consideraciones anatómicas y fisiológicas sobre el cuerpo. Además, muestran cómo se replicó esta verticalidad en la valoración social respecto a las relaciones entre el cuerpo humano 
y el cuerpo animal, el cuerpo humano y los artefactos, a lo largo de la historia de occidente. Por ejemplo, este sentido de verticalidad puede verse extendido al orden jerárquico para la comprensión del cuerpo humano a lo largo de las sociedades de occidente desde las épocas iniciales de Grecia y Roma, hasta las sociedades europeas de la entrada al siglo XX, manifestación no, en sentido lineal, sino evidente en las dinámicas históricas de su transformación. Los estudios del volumen I (Nadaf, Tazi, y Feher, V.III (pp.158-179; 351-394) muestran el desarrollo de concepciones sobre el sentido disfórico y el sentido eufórico de las relaciones del ser humano con la naturaleza y con el mundo, y el juego de oposiciones simbólicas que dichas concepciones otorgaron para la comprensión del cuerpo en occidente. A partir del análisis se pudo establecer que estas dinámicas dicotómicas, basadas en concepciones disfóricas y eufóricas sobre el cuerpo humano, cimentaron y dieron las razones para valorar el cuerpo, sus aspectos, estudios, realidades y representaciones, a partir de un orden vertical de jerarquías, el cual, se encontró no solo en los estudios del primer volumen, sino a lo largo de todos los estudios de los Fragmentos. En este punto del análisis fue evidente que aun cuando el sentido dual o dicotómico de las concepciones sobre el cuerpo en occidente, sufrió transformaciones en correspondencia con las condiciones de cada época, su esencia como un modo de relación desintegrado o divisorio se mantuvo, aunque ya re-significado, hasta la entrada al siglo XX.

Esta primera evidencia del análisis motivo la reorganización de los estudios que componen la fuente en mención, a partir de la cual, fue posible establecer cómo las concepciones duales estaban concretadas socialmente como claras diferenciaciones o disgregaciones de condiciones y aspectos del cuerpo, a la manera de condiciones no visibles o espirituales y condiciones visibles o materiales. Esta diferenciación se reveló como una recurrencia subyacente en los diferentes estudios, como una forma de lógica sobre la cual se sustentaba la organización de los distintos aspectos, cualidades y componentes corporales en un orden jerárquico vertical, de arriba hacia abajo, con gradaciones de valoración, entre sobre y sub valoraciones respecto a dichas condiciones.

Así que, el enfoque vertical referido por los autores, no solo abarcaba los estudios reunidos en el primer volumen, sino también los demás estudios de los volúmenes II y III. La predominancia de este enfoque en los tres volúmenes, es decir, la presencia lógica de la jerarquización del cuerpo en la gran mayoría de los estudios compilados, revela dicha jerarquía como un modo a través del cual, las sociedades estudiadas se relacionaban respecto al cuerpo, si nos atenemos a que dichos estudios, en su gran mayoría, presentaron el tratamiento de los distintos temas específicos, a partir de indagaciones documentales referidas a la experiencia de ser cuerpo, en las distintas épocas y sociedades. Y esta es una de las revisiones críticas que se hace a la fuente, pues la sospecha de modos de construcción del cuerpo que se continúan en el tiempo, mencionada por los autores, más que la idea de construcciones, me parece que están mayormente conectadas con la persistencia de estos modos de relación con el cuerpo, que se establecieron a partir del ordenamiento jerárquico vertical, bajo las lógicas de lo visible, material y lo no visible, inmaterial.

Las condiciones corporales no visibles fueron valoradas como las más altas y las de arriba, visuales-mentales; las segundas, como las de abajo, las más animales, las gástricas y reproductivas. Bajo esta comprensión dual del cuerpo presentada a lo largo de los tres volúmenes, se muestra cómo se jerarquizaron los componentes corporales matéricos, orgánicos, físicos, de género ${ }^{5}$, espaciales, psicológicos, comportamentales y sociales, según ordenes de visibilidad o no visibilidad, según el órgano y la función, según el lugar del cuerpo que com- 
prometían, según la condición sexual que involucraban. Es decir, que se hizo evidente que las concepciones duales sobre el cuerpo tomaban forma social en las maneras de la experiencia social del ser cuerpo: dicha experiencia era valorada desde este sistema de jerarquías ${ }^{6}$.

El siguiente paso en el análisis fue un ejercicio de comparación por asociación de los resultados de los distintos estudios y ejes problémicos, para establecer correspondencias entre las concepciones duales y las valoraciones jerárquicas ya encontradas, esta vez, interrogando la relación con las dinámicas de representación poética o prosaica del cuerpo en las distintas épocas y sociedades referidas por los estudios.

El análisis mencionado arrojó como resultado que tanto las concepciones duales sobre el cuerpo, como las valoraciones jerárquicas de la experiencia social del cuerpo, se extendían a la vez en las representaciones poéticas y prosaicas del cuerpo generadas por las distintas sociedades. En particular, para el caso de las artes plásticas, se pudo establecer que tanto las concepciones duales, como las valoraciones jerárquicas se proyectaban o se re-significaban a manera de un estatuto para la representación corporal -estatuto corporal- , basado en divisiones o fragmentaciones simbólicas de la dimensión espacial en los procesos de representación de la imagen de cuerpo. Dichas fragmentaciones simbólicas como sistema de representación plástica de la imagen con sus correspondientes transformaciones históricas conservaron, sin embargo, la regencia anatómica o biologista de la forma humana durante siglos, hasta los cambios más rotundos al respecto en la representación de la imagen de cuerpo en los albores del siglo XX.

Un tercer momento en la configuración del criterio de modos de relación, consistió entonces en el análisis de los demás ejes problémicos de la fuente estudiada, pero esta vez ya para indagar estas relaciones posibles entre las concepciones duales, las valoraciones jerárquicas, y las dinámicas de representación del cuerpo, según distintas épocas y sociedades presentadas por los estudios.

Por ejemplo, en el segundo volumen de la obra citada, con el eje problémico de adentro y afuera, los estudios explicitan según los autores, el modo de construcción del cuerpo, respecto a la condición matérica- carnal, y a la condición espiritual, que hacía referencia a preguntas y respuestas sobre lo visible y lo invisible del cuerpo, la materia y el alma, la emoción y el gesto, el erotismo y la muerte, la anatomía y el psiquismo, el placer y el dolor, el sacrificio y la espiritualidad, etc. Lo anterior en ámbitos corporales en relación con las costumbres, las investigaciones y las representaciones artísticas de cada época. La interpretación de las emociones que hacen los autores de la fuente en este eje, se basa en lo que denominan (1992) "enfoque transversal psicosomático", argumentando que los estudios allí compilados se llevan a cabo "de adentro hacia afuera" del cuerpo. Los estudios se centran en el principio vital que según los autores ha sido denominado el alma humana en el mundo occidental.

Sin embargo, en búsqueda de las relaciones entre concepciones, valoraciones y representaciones del cuerpo, en este punto del análisis fue posible interpretar la localización del orden jerárquico de valoración de la condición no visible o espiritual, en partes concretas y lugares puntuales del cuerpo físico, así como en formas del comportamiento humano. Es decir, la concreción o incorporación en partes, lugares, acciones y gestos del cuerpo físico, de la proyección de "divinidad", "gracia", "espíritu", "alma"; según los autores, en aquello que se moviliza en el cuerpo, y el tipo de disciplinas que se imponen para producir el alma de un héroe, un cortesano, un santo, etc. Esta proyección caracterizó la valoración del comportamiento humano en las primeras sociedades occidentales (tal como se ejemplificó al inicio de esta reflexión desde el caso específico de las lógicas de la Fisiognomía), y que como se muestra 
en Fragmentos para una Historia del Cuerpo, posteriormente entre los siglos XVI y XIX, se transformó con un entramado pisco-físico de valoraciones definidas, asociadas a las mismas? desde las cuales se comprendió y se ejerció la experiencia de cuerpo, esta vez desde la aparición de normativas comportamentales y pedagogías del cuerpo.

Muchas de las relaciones propuestas por este entramado, a manera de estructura estructurante, modelan aún hoy, modos del ejercicio de las inter-corporeidades, no solo en la vida social, sino también en la valoración de los aspectos visibles o no visibles, por ejemplo, de la obra artística: en tanto presencia y significación.

En el tercer volumen del libro citado se presentan los estudios que tratan "la relación entre órgano y función." Alli se referencian las diferentes valoraciones de las metáforas corporales hechas a partir de funciones, órganos o fluidos del cuerpo, así como la extensión simbólica de dichas valoraciones en múltiples metáforas extendidas en la valoración del cuerpo del individuo como perteneciente al cuerpo social.

Finalmente, uno de los aspectos más relevantes en la tercera parte del análisis fueron las conclusiones referidas a cómo estas lógicas de valoración desde los significados de la relación órgano-función, fueron reproducidas como premisas básicas sobre las que se conformó el lenguaje de las artes plásticas y visuales, en la valoración por jerarquías de importancia, por ejemplo, de modos de composición, del cuándo y el cómo del uso de los colores y sus significaciones, direccionalidades de líneas, ordenamientos de planos; valoración de las relaciones de figura y fondo; valoración de las cualidades de las materias y los materiales, así como el ordenamiento político de elementos del contenido y del continente; valoración simbólica política de la luz y la sombra, así como la supremacía de la mirada masculina en la representación de la imagen del cuerpo en occidente que llega incluso hasta mediados del siglo XX, así como la escasa participación de las mujeres en los ámbitos artísticos, en los siglos anteriores.

Como resultado de todo este proceso comparativo entre aspectos experienciales y aspectos teóricos de reorganización y análisis crítico respecto de la idea de modos de construcción del cuerpo sustentada por los autores, fue posible contraproponer entonces, la perspectiva de modos de relación con respecto al cuerpo.

A partir de la comparación entre la dimensión experiencial de la investigación, y el hecho de asumir desde los estudios críticos de la corporeidad, que la experiencia corporal es siempre experiencia políticamente encarnada, situada y contextualizada, fue entonces revaluada la idea de modos de construcción más como modos de relación respecto al cuerpo, al restituir desde el análisis, a los sujetos que dan forma a las sociedades; pues no son la ciencia, el arte y la vida cotidiana, sujetos animados que realizan modos de construcción de cuerpo. Son los sujetos de la experiencia quienes llevan a cabo los intercambios vitales de las inter corporeidades a partir de sus facultades del pensar, el sentir y actuar (Rico Bovio, 1999), así como de las facultadesestésicas y semiósicas (Mandoky, 2006), a partir de cuyas dinámicas se producen representaciones de cuerpo en los ámbitos de las poéticas artísticas y las prosaicas cotidianas.

Concluyendo, el criterio modos de relación respecto al cuerpo o modos de relación sintiente (Castillo, 2012), fue configurado así:

busca comprender las tramas complejas de tensiones vitales que tejemos en las interacciones humanas en tanto seres corporales, a partir de los intercambios de todo orden que conforman las realidades que construimos desde las dinámicas de la existencia personal, colectiva, social, cultural, histórica y ambiental. En dichas tramas de la existencia humana, las dinámicas de concepción respecto a la condición corporal (ideas, conceptos, imaginarios, 
creencias, opiniones, discursos, etc.), se extienden y se ponen en marcha, a manera de dinámicas sociales de valoración de dicha condición que se mueven a través de la experiencia política de la existencia. El orden más o menos jerárquico de dichas valoraciones modela o da forma a los regímenes u órdenes corporales a través de los intercambios de las sensibilidades -inter-sensibilidades-

Tanto las dinámicas de concepción, como las dinámicas de valoración dan sentido y se manifiestan en las dinámicas de representación de la condición corporal que se llevan a cabo y que circulan respectivamente en las artes, las culturas y las colectividades, a través de la "poética", la "prosaica" (Mandoky, 1994) y los procesos de "creación social" (Castoridis, 1975).

Para el proyecto Anatomías sentimentales, el criterio de modos de relación sintiente, resultó ser un recurso propicio para un tipo de análisis más pertinente y coherente con la naturaleza misma del performance, pues permite una interpretación dinámica de la condición corporal, desde el 'ir siendo' en el intercambio entre nuestra 'yoidad' in-corporada a partir de lo personal de la experiencia corporal, y los atisbos fugaces de ser condición corporal plural, histórica, colectiva, social, ambiental.

La aplicación de este criterio permitió darse cuenta de que los conocimientos o saberes en sí mismos procuran y actualizan en la vida social los modos específicos y característicos de relación respecto de las inter-sensibilidades, los cuales fundan a la larga, los dispositivos cuerpo a cuerpo, mediante los cuales las pragmáticas humanas de regímenes de conocimientos y sistemas de saberes intervienen en la condición corporal del mundo de la vida.

En el modo de relación desintegrado y vertical propio de la modernidad, las dinámicas racionalistas de concepción de la vida basadas en la oposición entre naturaleza y cultura, mente-cuerpo, masculinidad y feminidad, hombre y mujer, etc., han conllevado todo un sistema de dinámicas bio-políticas de valoración jerárquica de la existencia, manifiesto en las luchas cuerpo a cuerpo que como humanidad hemos establecido con el mundo de la vida.

Las concepciones y valoraciones de este modo moderno de relación desintegrada respecto al cuerpo se manifiesta en las dinámicas de las representaciones del mismo, que alimenta el sistema humano de las desigualdades tanto en la vida social, como en las representaciones fragmentarias del cuerpo que producen las perspectivas disciplinares; las representaciones jerárquicas de cuerpo del sistema guerra y las representaciones fragmentarias del cuerpo y sus sentidos en las artes. Una revisión crítica de las prácticas de formación artística al interior del campo, implica la indagación sobre cómo las artes participan de la reproducción del modo de relación vertical y desintegrado que ha caracterizado al régimen de la racionalidad bio-política, con respecto del cuerpo. Es a través de los intercambios de todo orden entre las distintas manifestaciones de lo viviente, como se reproduce la vida. El sentir conlleva la acción misma del estar presente y ser presente en cada circunstancia. Es a través del aprender a sentir, como aprendemos a morar en lo que conocemos como 'yoidad', y desde allí ejercemos los modos como habitamos e inter-actuamos con el mundo, los espacio-tiempos, los lugares, los encuentros. Aprender a sentir conlleva dos acciones de sujeción: una sujeción estésica en tanto incorporamos modos de ver, palpar, oler, oír, comer, respirar, de interacción con los otros, etc.; pero este modo conlleva una segunda sujeción, del orden semiósico, en tanto incorporamos los significados de dicho modo. Tal vez acciones políticas de deconstrucción de los modos como aprendemos a sentir, puedan contribuir a que nos demos cuenta y demos cuenta de la condición corporal de la existencia del mundo de la vida y de nuestra propia existencia como especie. 
Una reflexión sobre las artes como rutas posibles para la indagación de lo sensiblesintiente

Lo señalado anteriormente equivale a decir que hoy los procesos de representación en relación con el cuerpo, en artes o en estéticas de la vida cotidiana, lejos de ser el simple ejercicio de aplicación de una técnica, o el derroche de talento, constituyen en sí mismos, dispositivos histórico-sociales críticos que dan cuenta, deconstruyen y renuevan maneras como sentimos, interactuamos y pensamos, respecto al cuerpo.

Para el campo artístico y cultural colombiano la pregunta por los modos de relación, que son instituidos a través de las artes, conduce a interrogar sobre las dinámicas de representación, de valoración, y de concepción del cuerpo que son puestas en circulación en la vida social a través de las artes.

Las representaciones acerca del cuerpo, por constituir en sí mismas procesos creativos desde el orden de lo sensible-sintiente, evidencian el acontecer de las valoraciones de los cuerpos como no lo pueden atestiguar otras lógicas académicas desde los procesos deductivos, inductivos, etc., pues las imágenes, sea cual fuere su naturaleza: visual, plástica, sonora, etc., nos hacen un llamado directo a nuestros sentidos. Las imágenes de representación del cuerpo nos informan y nos confrontan cuerpo a cuerpo con los modos de relación sintiente que ejercemos respecto a la condición corporal de la existencia. Ellas en sí mismas constituyen maneras de sistematización de modos de relación sintiente, en circunstancias históricas específicas.

El predominio del modo de relación vertical y desintegrado respecto al cuerpo desde el régimen bio-político se hizo manifiesto en los procesos de autonomía del arte y de la ciencia, los cuales comparten la cuna común de concepciones duales y valoraciones por jerarquía respecto al cuerpo. La vigencia de estas lógicas repercute en las tensiones aún vigentes entre la asignación histórica de la tarea de la investigación del mundo, y sus relaciones asociadas a las ciencias y a la creación a las artes, esta última desde una pretendida finalidad no externa, sino enfáticamente interna, fundamento este, que por demás, ha tenido sus consecuencias en el desarrollo tardío de la contribución que la investigación artística puede hacer, respecto del estudio de los modos del ejercicio humano y ambiental de las inter-sensibilidades

De hecho, la vigencia de estas lógicas aún reproduce la repartición de los sentidos a cada una de las artes. Estos tomaron forma definitiva durante los procesos de autonomía del arte, cuando se clasificaron por un lado, los signos y las acciones del orden sensible-sintiente en naturales o de condición sensitiva ${ }^{8}$ como la pintura y la música; y de otra parte, los signos abstractos artificiales, como formas discursivas del habla y las representaciones abstractas. Se clasificaron también las acciones en signos arbitrarios, como la poesía, basada en acciones de carácter progresivo eminentemente temporal; $y$, signos naturales, basados en acciones simultáneas en un mismo momento en el espacio, como la pintura. Se establecieron diferenciaciones de aspectos sensibles entre lo plástico y lo pictórico, de lo háptico y lo táctil, entre otras. Así que, a partir de esta clasificación en las artes plásticas y visuales les fueron asignando por siglos, con sentido enfáticamente espacial, las cualidades perceptivas correspondientes inicialmente a lo táctil-visual y posteriormente a lo visual.

Las dinámicas de valoración bio-política de los cuerpos según componentes orgánicos, físicos, o condiciones de género, comportamentales, políticos y sociales, se proyectaron tam- 
bién en las artes plásticas y visuales, dando lugar a un estatuto corporal básico del lenguaje de dichas artes, dónde se asumieron estas mismas jerarquías para la valoración simbólica de materiales y elementos formales, como espacialidad, direccionalidades, relaciones de composición, medidas, perspectivas y cánones ${ }^{9}$. Muchas de estas valoraciones aún perviven hoy en la formación de artistas. Destaco en particular el sentido sexista y de género que marcó las dicotomías en la base de este lenguaje. En las dicotomías de valoración de aspectos físicos (Nadaf y otros, 1992, Vol I, p. 88) de materiales plásticos, tales como temperatura, luz, color, texturas, y de aspectos como ubicación y direccionalidad, la condición de los géneros marcó dualidades entre lo comprendido como condición femenina y condición masculina. Así, lo femenino fue comprendido en una relación simbólica de características como frío, oscuridad, rugosidad, seco; abajo, izquierda, atrás, horizontalidad. Este orden simbólico de lo femeninoabajo compartía el mismo entramado de valoración con las funciones de reproducción, las funciones gástricas, y las funciones sensibles. La construcción de lo femenino, representado socialmente en la mujer, estuvo asociado con las nociones de abajo = tierra= tridimensionalidad $=$ carnalidad $=$ organicidad $=$ materialidad $=$ pasión $=$ bajas emociones y sentimientos $=$ animalidad. Lo masculino por su parte, representado socialmente en la noción de hombre, estuvo asociado a las nociones de arriba, cielo = función visual-mental $=$ bidimensionalidad $=$ inmaterialidad $=$ significado $=$ el pensamiento $=$ hombre. Lo anterior revela cómo el orden de lo sensible-sintiente en las anteriores escalas de valoración estuvo en sus orígenes asociado con lo femenino, mientras las funciones de la razón a lo masculino.

Por su parte, la representación de lo masculino en el lenguaje plástico se concretó en características como: cálido, claro, liso, húmedo, arriba, derecha, adelante, verticalidad. En últimas, la construcción social tanto de la ciencia, como del arte, comparten en sus orígenes un mismo orden corporal sexista y generizado, con arraigo histórico en cuanto a la repartición y ordenación social del trabajo y de las clases sociales, la clasificación de los mundos y las razas, los procesos de domesticación, no solo de los cuerpos humanos, sino de domesticación, depredación y aniquilamiento del agua, de las plantas, del aire, y de las especies.

La performatividad histórica de la incorporación social del orden corporal dicotómico, jerárquico y de la disección, se manifestó en las entrañas mismas de la representación histórica del cuerpo en la plástica, en fragmentaciones simbólicas de la dimensión espacial, tales como: la fragmentación entre el espacio de la imagen y el espacio del espectador, es decir, entre bidimensión y tridimensión ${ }^{10}$ (que da origen a la unidad simbólica y funcional del cuadrado visual aún predominante en toda forma de pantalla. Debray, 1994), en la fragmentación entre figura y forma; forma y materia; fondo y figura; así como en la fragmentación de la figura humana para la representación, en cabeza-rostro-mirada y resto del cuerpo; además de divisiones simbólicas por leyes de composición, perspectiva, cánones y medidas.

Todo este proceso, señala Ramírez (2003) ${ }^{11}$ que alcanza su clímax en la fragmentación de la dimensión espacial en planos, y el tiempo en facetas, en el límite del siglo XIX y el XX. Sin embargo, es posible desde la lógica del criterio de modos de relación sintiente, interpretar la concreción social del régimen visual-mental en el desarrollo de los medios visuales y audiovisuales como medios que dan cuenta, a lo largo del siglo XX y lo que va corrido del XXI, del énfasis en la visualidad y su modo sensible-sintiente, como modo por excelencia que ha acompañado la perspectiva racional. 
Aplicando el criterio de Modos de relación más críticos respecto al cuerpo a esta última fuente citada, es posible interpretar durante el siglo XX y XXI Modos de relación más críticos respecto al cuerpo: donde las dinámicas de concepción y de valoración de la condición corporal adquieren una comprensión más compleja como campo de tensiones existenciales, culturales, psíquicas, energéticas, políticas, sociales, ambientales, étnicas y de género, etc. Lo anterior, proyectado en el énfasis de las dinámicas de representación del cuerpo en las artes plásticas y visuales, así:

En la primera mitad del siglo XX, un énfasis temporal-espacial, donde mientras de una parte, la unidad operativa plano-faceta resumió e instituyó a través de los nuevos medios visuales, el lenguaje de fragmentaciones espaciales simbólicas provenientes de los siglos anteriores para la representación del cuerpo, de otra parte, la unidad anatómica espacial de la imagen representada de cuerpo, se fragmentó en múltiples planos, facetas y puntos de vista con la consecuente relativización de la preponderancia espacial en la representación del mismo. Los registros de los medios permitieron llevar al cuadrado visual a la pantalla o al encuadre fotográfico los cuerpos humanos en distintas realidades y condiciones políticas, étnicas, sociales, sexuales y de género.

El uso antropológico de los medios durante la primera mitad del siglo XX, favoreció otras concepciones del cuerpo al evidenciar la pluralidad mundial de condiciones políticas y realidades corporales, además de dar paso a una consciencia estimativa del predominio hasta entonces de la valoración de la mirada masculina sobre la representación del cuerpo femenino, así como la evidencia de grandes diferencias en mundos y formas de comprensión del cuerpo, y los primeros registros del tratamiento violento de los cuerpos por la guerra, etc. Una vez rota la enfática de la forma anatómica humana en la representación del cuerpo, las dimensiones del sueño, el recuerdo, el desvarío y el azar fueron utilizadas como recursos desde las artes plásticas, para deconstrucciones poéticas del imperio de la razón.

Durante los dolorosos escenarios de violencia contra la condición corporal de la segunda mitad del siglo XX, emerge un énfasis en la condición actuante del cuerpo en la plástica, esta vez en acción inter-disciplinar con otras artes. En la re-significación de las acciones creativas de las artes del cuerpo, la representación se tornó en presentación desde donde los artistas, usando sus propios cuerpos como metáfora política, interrogaron sobre los modos de valoración del cuerpo por la guerra, interrogaron sobre las concepciones anatomistas para el mismo, así como acerca de las estructuras monoculares del régimen bio-político, anteponiendo a estas, como elementos del lenguaje, las condiciones sensibles-sintientes, así como la memoria, la sexualidad política, la interacción y el movimiento.

Para finales del siglo XX y lo que va del XXI, es recurrente en la representación del cuerpo un Énfasis en la re-construcción o incorporación: a manera de un énfasis espacial-carnal en la re-presentación, no basado en la fragmentación de la unidad anatómica espacial de la imagen de cuerpo como a comienzos del siglo $\mathrm{XX}$, sino en una intencionalidad de fragmentar la unidad anatómico identitaria al incorporar en el cuerpo propio, partes u órganos de otros cuerpos, así como otras identidades y otros géneros. Las artes del cuerpo dan cuenta a través de su re-presentación de los cuerpos, del resquebrajamiento social, lento, pero en proceso, de la perspectiva anatomo-política de los cuerpos, en particular de las categorías de género, roles sociales y sexualidades, y de las cualidades de pensamiento y emotividad que se les han asignado históricamente. 


\section{ALGUNOS RESULTADOS DE LO INDAGADO DESDE LA EXPERIENCIA}

Según se pudo diagnosticar en estudios sobre tratamientos del cuerpo en procesos de formación de artistas plásticos en Colombia durante la primera década de este siglo ${ }^{12}$ se da una re-producción de manera acrítica de aspectos que refieren la vigencia que tienen los distintos modos de relación anteriormente descritos. Esta reproducción trae como consecuencia, el hecho de que los sujetos artísticos en formación son asumidos como in-corpóreos, no historizados, sin contextualización, sin condiciones de género, con subjetividades destinadas puntualmente a la producción de obra, etc.

La no-corporeidad del sujeto artístico en la comprensión del arte, propio de la modernidad, se halla en correspondencia con la mono focalización que el sistema de las artes puso en los valores estructurales de la obra: perceptivos, emotivos, morales, anímicos; la emoción estética, el placer de la ilusión estética, la finalidad interna y externa, el desinterés etc. Para el caso de la formación de artistas plásticos en Colombia, la actualidad de estas valoraciones contrasta con las realidades de las violencias contra los cuerpos, que son estructurantes de la cultura de la agresión en nuestro contexto, y de la voz del más fuerte como mecanismo de construcción y ejercicio de las identidades en el país (Larraín, 1996). En tensión con estas realidades, en la investigación se asumió la posibilidad no del performance como una técnica más para la producción de obra, sino en su sentido crítico de performatividad de géneros, identidades, subjetividades y colectividades. Mediante el perfomance y las corpografías pude constatar que los sujetos artísticos en general, y en particular, las mujeres, establecieron otras maneras distintas de relacionarse respecto al 'cuerpo', las cuales, aun cuando no eran visibles a primera vista por la relevancia del orden académico en la producción de obra, sí trascendían la representación académica del cuerpo como cosa-anatómica interpretada desde escalas, cánones, proporciones y perspectivas, técnicas y discursos.

Uno de los resultados más destacados de estos procesos, fue la evidencia de que las mujeres proyectaron valoraciones acerca de experiencias de su existencia corporal en representaciones que tenían en general relaciones estésico - semiósicas entre afectividades y temporalidades, las cuales se manifestaron a través de enfáticas lexicales y somáticas. Se evidenció un contraste, pues mientras estas manifestaciones tenían un sentido vinculante, que aludía a la experiencia corporal de manera integral, durante los procesos de narración o puesta en performance a propósito de las mismas, durante la manifestación plástica de dichas experiencias, la enfática se daba en la asociación del sentido afectivo de cada experiencia con un lugar o parte de la imagen de cuerpo representado, donde la dimensión temporal de lo vivido menguaba, y se establecía en cambio, una relación de fragmentación con la imagen representada a manera de una anatomía sentimental, que si bien conservaba la distribución anatómica de la figura humana en dicha imagen, cambiaba radicalmente en sus significaciones. La ubicación de los sentimientos y emociones de lo vivido, otorgaba a los lugares del cuerpo otras significaciones, las cuales en la gran mayoría de los casos superaba la perspectiva anatomista del órgano y la función. Por citar un ejemplo, los lugares del 'miedo' en el cuerpo fueron identificados distintamente, según las experiencias vividas, en: las rodillas, en las uñas, en los labios, en la boca del estómago, en la espalda, en el talón, en la boca, entre otros. Aquí la deconstrucción de la imagen bio-política del cuerpo aludía a la dimensión estésica, dando como resultados, en la mayoría de los casos, anatomías sentimentales femeninas que deconstruyeron la representación del cuerpo como objeto, y adquirieron más un sentido de 
reconfiguración o restitución de aspectos de la propia subjetividad sobre todo, respecto a la condición política emotiva de la existencia.

Mientras las representaciones plásticas de la experiencia de cuerpo vivido configuraron una anatomía del sentir, las representaciones de la experiencia vivida a través del performance tomaron las rutas de la representación de las temporalidades vividas de "las otras que se ha sido" o de la condición plural de la experiencia corporal de la existencia, a través de la enfática afectiva de acústicas, cinéticas y somáticas (gestos, ironías, perífrasis, posturas, entre otras). Las anatomías sentimentales resultaron entonces ser una especie de acción de desnudamiento o de despojo de sí mismas, que fue cedida a la imagen representada a manera de investidura, mientras que durante las pluri-corporeidades que arrojó el performance, cada participante integró en la presencia espacial de su condición corporal, la actualización de otros tiempos vividos de la infancia, la juventud, etc., o de las otras corporeidades vividas.

Respecto a las concepciones en relación con la condición corporal se encontró, que en general cada mujer participante se moviliza entre multiplicidad de concepciones, inclusive aparentemente opuestas, que cubren un intervalo entre concepciones 'educadas' y disciplinares del cuerpo, es decir, el cuerpo aprendido en los procesos educativos, concepciones religiosas arraigadas y muy frecuentes, concepciones de género también disímiles entre perspectivas tradicionales, de tendencia feminista o de ámbitos culturales específicos. Sin embargo, se hizo evidente que las mujeres establecían relaciones a manera de matrices grupales muy definidas, las cuales emergieron a partir del compartir las experiencias de lo vivido en una especie de solidaridad colectiva por encontrar recurrencias comunes en la experiencia social de ser mujeres, relacionadas con vivencias de prácticas de agresión, maltrato físico, sexual y psicológico, racismo y discriminación.

En términos generales, esta pluri-concepción daba paso a las posibilidades de transformación de las participantes en cada una de las experiencias creativas a través del performance o de las corpografías en dinámicas de representantes en doble vía: por un lado, auto-representativas y auto-referenciales para sí mismas, y representantes de sí mismas en la imagen de cuerpo creada. De tal manera que, las dinámicas creativas constituyeron en sí mismas un modo de relación sintiente desde la actualización, donde las acciones y las actuaciones realizadas por las mujeres durante el proceso creador les permitieron actualizar lo vivido a partir del intercambio entre la temporalidad presente de las estesis alcanzadas mediante técnicas y materiales, y la trans-temporalidad de las semiosis o juegos de significación entre las experiencias del haber sido, el ir siendo la posibilidad de re-crearse.

En este modo de relación de la actualización que se hizo evidente durante la ejecución de los procesos creadores, las dinámicas de representación tuvieron un carácter vinculante entre procesos de desnudamiento y de investidura mediante los cuales, en sentido metafórico, las participantes des-visten para in-vestir de otras maneras posibles las dinámicas de su vida personal, ante sí mismas y para los otros.

Estos modos de relación desde la actualización de sí mismas dejaron ver la condición política de los procesos creadores a través del performance y de las corpografías, pues aquello que se desviste y se inviste resulta a la larga ser la simbolización de la propia piel, ya que en los procesos de auto-representación corporal, recurrentemente se manifestaron como representación en una superficie, donde las participantes vistieron, maquillaron, cortaron, rasgaron, cosieron, lloraron, besaron, pegaron, decoraron, rasguñaron, pintaron, perfumaron, acaricia- 
ron, etc. La percepción de olores, sabores y colores estuvo estrechamente relacionada con las descripciones del recordarse a sí misma y a las vivencias propias. Aquí las acciones creativas se revelaron en la performatividad de los géneros. Se evidenció una recurrencia a la generalización en la representación propia del modo artístico ya descrito, en la línea de masculinidad. En la auto representación en línea femenina se destacó el detalle en la valoración y asignación simbólica de materiales, colores y lugares sobre las corpografías, según el nivel de afectación de experiencias de lo vivido.

En la auto-representación, los eventos narrados respecto al cuerpo vivido fueron organizados en dos grandes rasgos: cuerpo amado y cuerpo maltratado. Las auto- representaciones de cuerpo maltratado, de recurrencia destacada en la representación de línea femenina, indican en el espacio físico de la imagen representada, el objeto con el que se hizo la agresión, o aluden al agresor; en menor recurrencia se detienen a tratar de describir la sensación vivida como totalidad. Sin embargo, en la descripción verbal de la experiencia, las artistas enfatizan en las sensaciones y sentimientos que dichos eventos agresivos produjeron en ellas.

Es decir, desde las inter-sensibilidades propias de las acciones de narrar lo vivido -a través de prácticas del performance-las mujeres establecieron modos de relación basados en dinámicas de valoración desde las temporalidades vividas, se valoraron a sí mismas desde la pluralidad de las otras que han sido o quieren ser, revelando la rotura de concepciones de 'unicidad' respecto de sí mismas. Estas valoraciones temporales y pluri corporales estuvieron asociadas a enfáticas en la representación, referidas a las afectividades, a la representación de sus emotividades.

Por su parte, en los modos de representación realizados, a través de las grafías, sobre cualquier superficie, a manera de auto retratos, (en la mayoría de los casos) se mantuvo la

enfática anatómica en la representación del cuerpo. Las afectividades y emotividades fueron asociadas a partes y lugares de esta forma anatómica, sin embargo, se revela una anatomía emotiva propia. Aquí el modo de relación, resume concepciones anatómicas, valoraciones por jerarquías espaciales y representaciones de corpografías políticas, que contrasta con la regencia anatómica de la forma.

Durante este proceso de investigación emergieron también modos colectivos de relación sintiente, donde quienes participaron se dieron cuenta y dieron cuenta de aspectos comunes de sus estesis, a partir de semiosis compartidas en relación a modos de la experiencia de cuerpo en las interacciones sociales. Por ejemplo, las narraciones acerca del cuerpo maltratado generaron reacciones colectivas como llorar juntos, abrazar, gritar, guardar silencios largos, etc. Los resultados tanto de los modos de relación desde la actualización como de los modos de relación colectivo constituyeron las fuentes para posteriores procesos creadores desde performance críticos, respecto a la condición primordial sensible-sintiente de la condición corporal humana, enfáticos en las somáticas de llorar, gritar, silenciar, besar, etc.

Los momentos de consciencia estimativa de la condición de la experiencia, interpretada a través del criterio argumentado, a partir de prácticas de performance y corpografías, como uno de los resultados del proyecto pueden resumirse así:

De las memorias de las experiencias de existencia corporal vivida al auto-reconocimiento de la condición estésica mediante las actualizaciones sensibles-sintientes que procuran las actuaciones creativas: consciencia crítica sobre el aprendizaje incorporado sobre los límites de cómo ser y sentir como mujeres. 
De la condición estésica auto reconocida al revestimiento corporal de la imagen de cuerpo que se crea a través de las acciones creativas: la posibilidad instituyente de otras dinámicas de la existencia, hasta ahora imaginadas y no exploradas.

De la imagen de cuerpo representado a través de poéticas y prosaicas, como espejo auto referencial y semiósico, a la posición de espectadoras críticas de la condición política de su corporalidad sintiente, esta vez, auto reconocida.

Del auto reconocimiento de la condición política del sentir, a la posibilidad restituyente de la auto representación de 'sí mismas', no limitada a la regencia bio-política sobre lo femenino históricamente vulnerada en valoraciones de subordinación, desigualdad y dependencia, sino fundada en el ejercicio performativo de la propia condición sensible-sintiente de su existencia como condición de afectividad y afectación colectiva, ambiental e inter- sensible con el mundo de la vida, como condición temporal efímera de espacialidad, relativa a las presencias de los roles aprendidos, incorporados o impuestos por los órdenes corporales vividos, como condición de la existencia cuya capacidad de mismidad plural no se reduce a las simbólicas unívocas de las industrias del deseo, la maternidad, la domesticidad y la violencia; como condición plástica de la existencia modelable por dispositivos políticos de dinámicas de concepción, de valoración y de representación, lejos de la secuencia de estar y ser sujetos -únicos - singulares -racionales - universales.

\section{NOTAS}

1 Bourdieu define el habitus como un conjunto de disposiciones duraderas y transferibles, las cuales están predispuestas para funcionar como estructuras estructurantes, a la vez objetivamente reguladas y reguladoras, sobre las cuales refiere textualmente que:

La incorporación de las jerarquías sociales por medio de los esquemas del habitus, inclinan a los agentes, incluso a los más aventajados a percibir el mundo como evidente y aceptarlo como natural, más que a rebelarse contra él, a oponerle mundos posibles, diferentes, a aun, antagonistas: el sentido de la posición como sentido de lo que uno puede, o no, "permitirse" implica una aceptación tácita de la propia posición, un sentido de los límites o, lo que viene a ser lo mismo, un sentido de las distancias que deben marcar o mantener, respetar o hacerse respetar. (p. 289)

2 Con estudios acerca del Régimen bio-político en América Latina realizado por las obras ya citadas de Zandra Pedraza; Cuerpo fábrica del Yo, de Ana María Brigante, y Gustavo Chirolla, (2005), La teoría crítica de la corporeidad de Arturo Rico Bovio, la revisión crítica de la estética en Prosaica / y Prosaica // de Katya Mandoky (1994, 2006) y Modernidad, Razón e Identidad en América Latina, de Larraín (1996).

3 Entre ellos, El proceso civilizatorio de Elías, Norbert (1978), The body as representation and Being-in-the-World en Csordas (1996), Goffman (1987), acerca de La presentación de la persona en la vida cotidiana, Fragmentos para una historia del cuerpo humano por Ramona Nadaf, Nadia Tazi, y Michel Feher, (1992); Las memorias corporales de Piera Alugnier (1991); Estudios del proceso creador de Didier Anziu (1987), Epistemologia del sur de Sousa Santos (2009), Decolonizing Methodologies Research and indigenous people de Uhiwai Smith Linda (1999); Cuerpos que importan, sobre los límites discursivos y materiales del sexo de Judith Butler (2002).

4 Como el de Amelia Jones. El cuerpo del artista (2006); Francesa Alfano Miglietti en Extreme bodies (2003), The use and abuse of body in art, entre otros, La estética relacional de Borrieaud (2006); el trabajo de Juan Ramírez, Corpus Solus. Para un mapa del cuerpo en el arte contemporáneo (2003); Arte y acción, entre la performance y el objeto (1998) de Paul Schimell; El cuerpo de la obra (1999) de Víctor Fuenmayor, entre otros.

5 En Nadaf, Tazi y Feher, (1992, Vol I. pp. 163-226), Carol Walker Bynum muestra, por ejemplo, la subvaloración histórica de las mujeres, desde donde interpretamos como los modos de relación respecto al cuerpo que les fueron asignados por la tradición de occidente: madre, por asociación con María y por lo tanto cuidadora del 
cuerpo: enfermera, maestra, etc.; prostituta, como el ejercicio del cuerpo animal y pasional; bruja o loca: por una comprensión estrecha de la relación bio-psíquica de la mujer.

6 En ¿Cabeza o corazón? El uso político de las metáforas corporales durante la Edad Media, Le Golff argumenta (en Nadaf, Tazi y Feher, 1992, vol. VIII, p. 13):

La cabeza (caput) era ... entre los romanos, la sede del cerebro (...) la función dirigente (...) el sistema cristiano de metáforas corporales reposa sobre todo en la pareja cabeza-corazón...el valor simbólico de la cabeza se refuerza ... pues allí se halla enriquecido por la valorización de lo alto dentro del subsistema alto/bajo, expresión del principio cristiano de jerarquía (...) Cristo es la cabeza de la iglesia y Dios es la cabeza de Cristo

7 En la fuente en mención (pp.151, 154, 176) se muestra como:

Lo que en la edad media comenzó de manera rudimentaria en siglos posteriores se convierten en normas y medidas precisas para la postura física y el comportamiento. La nueva pedagogía del cuerpo y su postura y comportamiento buscaban referencias en la geometría del universo.

8 Según presenta Bozal, Valeriano en Historia de las ideas estéticas y de las teorías artísticas contemporáneas. Vol I, II. Madrid: La Balsa de la Medusa, 2000.

9 La representación en el canon griego, se enfocó en la medida de la cabeza, sede de la razón y del gobierno del cuerpo, en ella, la cara se interpretó como el epicentro de la personalidad y reflejo del alma, en ella el rostro, sede de la expresión espiritual. Con estas ideas, Panofsky argumenta cómo el rostro es asumido como unidad de medida y comparación del cuerpo y sus otras partes (Nadaf, Tazi, y Feher, 1992, Vol. I. p. 77).

10 En Nadaf, Tazif y Feher, (1992, Vol.II, p. 66):

(...) Plotino exhorta a los artistas a adquirir una "visión plana", del mundo sensible donde las figuras llevadas al primer plano escapen de los huecos y a los relieves de la tercera dimensión

11 Ramírez (2003, pp. 207-234) identifica la fragmentación visual en la representación del cuerpo a través del plano-faceta como fragmentación geométrica en el encuadre visual, un plano mental que se ha enfocado para destacarse

12 Ver estudio sobre Tendencias de la formación en Artes plásticas y Visuales a nivel nacional e internacional, realizado por la Universidad Francisco José de Caldas, 2009.

\section{REFERENCIAS}

Anziu Didier. El cuerpo de la obra. Ensayos psicoanalíticos sobre el proceso creador. Vol. 8. trad. Antonio Marquet por Flora Botton -Burlá. México: Universidad autónoma de México, Anuario de Letras Modernas, 1997.

Anziu, Didier. Funciones del Yo piel. [En línea] núm. 2. año 1, (nov 2001) http://www.vivilibros.com/ excesos/02-a-02.htm; (Acceso: 25 de mayo de 2009).

Bourdieu, Pierre. Sociología y cultura. México: Editorial Grijalbo, 1990.

Debray, Regis. Vida y Muerte de la Imagen. Barcelona: Paidós, 1994.

Gadamer, Hans. Verdad y método, trad. Ana Agud y Rafael de Agapito. Salamanca -España: Ediciones Sígueme, S.A. 1975).

Jones, Amelia. El cuerpo del artista. Londres: Phaidon Press Limited, 2006.

Larraín, Jorge. Modernidad, Razón e Identidad en América Latina. Santiago de Chile: Editorial Andrés Bello, 1996.

Mandoky, Katya. Prácticas estéticas e identidades sociales. Prosaica dos. México: Siglo XXI editores, CONACULTA- FONCA, 2006.

Martínez, Teresa y Delcán, Carmen Fisiognomía. Fisiólogo. Pseudo Aristóteles. Madrid: Editorial Gredos, 1999. 
Maturana, Humberto y Varela, Francisco. El árbol del conocimiento. Las bases biológicas del entendimiento humano. Santiago de Chile. Lúmen. Editorial Univeristaria, 2003.

Nadaf, Ramona, Tazi, Nadia y Feher, Michel. Fragmentos para una historia del cuerpo humano. Vol .I, II, III. España: Taurus Ediciones, 1992.

Pedraza, Zandra. "El régimen biopolítico en América Latina". Revista Iberoamericana. [En línea] IV, núm 15 (2004): 7-9. http://www.iai.spk-berlin.de/fileadmin/dokumentenbibliothek/ Iberoamericana/15-pedraza.pdf (Acceso: 25 de mayo de 2009).

Pedraza, Zandra. "En cuerpo y alma: Visiones del progreso y de la felicidad" Revista de Estudios Sociales, Universidad de Los Andes, Departamento de Antropología [En línea] (1999) http://res. uniandes.edu.co/view.php/193/view.php. (Acceso: 25 de mayo de 2009).

Ramírez, Juan. Corpus Solus. Para un mapa del cuerpo en el arte contemporáneo. Madrid: Editorial Siruela, 2003.

Rico Bovio, Arturo. Las fronteras del cuerpo. Crítica de la corporeidad. México: Editorial Planeta, 1990.

Rodríguez, Juan. Corpus solus. Para un mapa del cuerpo en el arte contemporáneo. Madrid: Editorial Siruela, 2003.

\section{Cómo citar este artículo:}

Castillo Ballén, Sonia. "Modos de relación sintiente bocetos hacia una perspectiva del performance como ruta metodológica para la indagación de subjetividades". Cuadernos de Música, Artes Visuales y Artes Escénicas, 10 (1), 129-150, 2015. http:// dx.doi.org/10.11144/Javeriana.mavae10-1.mrsb 